\title{
Teknologi Biogas dari Kotoran Ternak sebagai Sumber Energi Alternatif
}

\author{
Yeni Yusuf Tonglolangi \\ Program Studi Teknik Mesin-Fakultas Teknik-UKI Toraja \\ yulinary@yahoo.com
}

\begin{abstract}
Abstrak - Keterbatasan sumber energi menyebabkan manusia berusaha untuk mencari sumber-sumber energi baru, salah satunya adalah biogas.

Objek penelitian tahun pertama penelitian ini hanya difokuskan pada desain instalasi biogas dan memperkirakan volume biogas yang dihasilkan dari proses pengolahan kotoran ternak menjadi biogas melalui proses fermentasi dengan mencampurkan kotoran ternak dengan air 1:1, lalu dimasukkan ke dalam reaktor secara anaerob selama kurang lebih 2130 hari sehingga terjadi pembusukan hingga menghasilkan bio gas berupa $\mathrm{CH}_{4}, \mathrm{CO}_{2}, \mathrm{H}_{2} \mathrm{~S}$ dan gas lainnya seperti $\mathrm{N}_{2}$ dan $\mathrm{H}_{2}$.

Dari hasil penelitian, volume biogas yang dihasilkan dari kotoran kerbau adalah sekitar $1,84 \mathrm{~m}^{3} /$ hari. Sedangkan volume biogas yang dihasilkan dari kotoran babi adalah $1,004 \mathrm{~m}^{3} /$ hari.
\end{abstract}

Kata kunci - Kotoran Ternak, Biogas. Energi alternative

Abstract - Limited sources of energy, causes people trying to find new energy sources, one of which is biogas.

First year of this research object is focused only on the design of biogas installation and estimate of volume bioagas of processing manure into biogas through fermentation by mixing manure and water is $1: 1$, and then introduced into the reactor anaerobically for approximately 21-30 days thus producing bio-gas which includes $\mathrm{CH} 4, \mathrm{CO} 2, \mathrm{H} 2 \mathrm{~S}, \mathrm{~N} 2$, and $\mathrm{H} 2$.

From this research, the volume of biogas produced from buffalo dung is about $1.84 \mathrm{m3} /$ day. While the volume of biogas produced from pig manure is $1,004 \mathrm{m3} /$ day

Key Words - Manure, Biogas, Alternative Energy

\section{Pendahuluan}

Biogas adalah gas yang dihasilkan oleh aktifitas anaerob atau fermentasi dari bahan-bahan organik termasuk diantaranya kotoran manusia, ternak, limbah domestic (rumah tangga), sampahbiodegradable atau setiap limbah organik yang biodegradable dalam kondisi anaerobic. Kandungan utama dalam biogas adalah Metan dan Karbon dioksida $\left(\mathrm{CO}_{2}\right)$. Biogas memanfaatkan proses pencernaan yang dihasilkan oleh bakteri methanogen yang produknya berupa gas Metana $\left(\mathrm{CH}_{4}\right)$. Biogas juga dapat memberikan hasil samping berupa pupuk kompos yang dapat meningkatkan kesuburan tanah dan kualitas tanah karena sangat kaya akan sumber organic ${ }^{[13]}$.

Pada penelitian ini digunakan kotoran ternak babi dan kerbau karena Toraja terkenal dengan populasi babi terbesar di propinsi Sulawesi Selatan. Populasi ternak babi di kabupaten Tana Toraja dan Toraja Utara saat ini mencapai 454.298 ekor $^{[1]}$.

Biogas untuk skala rumah tangga biasanya memiliki komposisi seperti yang disajikan pada tabel 2.1.

Tabel 1. Komposisi Gas yang terdapat dalam Biogas

\begin{tabular}{|l|c|}
\hline \multicolumn{1}{|c|}{ Jenis Gas } & Volume (\%) \\
\hline Metana $\left(\mathrm{CH}_{4}\right)$ & $50-60$ \\
\hline Karbondioksida $\left(\mathrm{CO}_{2}\right)$ & $30-40$ \\
\hline $\mathrm{O}_{2}, \mathrm{H}_{2}$, dan $\mathrm{H}_{2} \mathrm{~S}$ & $1-2$ \\
\hline Sumber: Wahyuni $\mathrm{S}, 2008^{[13]}$ \\
\hline
\end{tabular}

Berdasarkan kisaran suhu aktivitasnya, bakteri dibagi menjadi tiga golongan, yaitu:

1. Tipe psikopilik, yaitu bakteri yang hidup pada daerah suhu antara $0^{\circ} \mathrm{C}-30^{\circ} \mathrm{C}$, dengan suhu optimum $15^{\circ} \mathrm{C}$.

2. Tipe Mesopilik. Bekerja pada suhu antara $25^{\circ} \mathrm{C}-40^{\circ} \mathrm{C}$. Dengan suhu optimum $33^{\circ} \mathrm{C}-35^{\circ} \mathrm{C}$.

3. Tipe Termopilik. Bekerja pada suhu reaksi antara $40^{\circ} \mathrm{C}-75^{\circ} \mathrm{C}$. Dengan suhu optimum $\pm 60^{\circ} \mathrm{C}$..

Starter yang mengandung bakteri Metana sangat diperlukan untuk mempercepat proses fermentasi anaerob. Beberapa jenis starter antara lain: (Indartono, S, Yuli, 2005)

1. Starter alami, yaitu lumpur aktif seperti lumpur kolam ikan, cairan septic tank, endapan lumpur (sludge) dan kotoran hewan.

2. Starter semi buatan, yaitu starter dari fasilitas biodigester dalam stadium aktif.

3. Starter buatan yaitu bakteri yang dikembangbiakkan secara laboratorium.

Dalam proses fermentasi yang merubah bahan organik menjadi gas Metan dengan bantuan bakteri (dalam keadaan anaerob) dapat dilalui melalui tiga fase atau tahapan yakni fase hidrolisis, pengasaman dan Metanogenik ${ }^{[3]}$ :

1. Fase Hidrolisis: Pada fase hidrolisis terjadi perombakan dan pemecahan bahan-bahan organik yang kompleks menjadi bahan yang sederhana dan mudah larut. Bahan karbohidrat kompleks akan dirubah menjadi monosakarida atau pelbagai gula sederhana menjadi peptida-peptida dan lipida/lemak menjadi asam-asam lemak dan gliserida.

2. Fase Pengasaman atau Asetogenik: Bahan yang terbentuk dari proses hidrolisis, yakni bahan-bahan yang lebih sederhana akan menjadi bahan makanan juga bagi bakteri terutama bagi bakteri pembentukan asam. Selanjutnya oleh bakteri bahan-bahan sederhana tersebut akan dirombak dan produk akhir yang terbentuk adalah asam-asam Asetat propionate, sedikit Butirat format laktat alkohol (Etanol) dan terbentuk pula sedikit gas Karbon dioksida, Ammonia dan Hidrogen. 
3. Fase Metanogenik atau Pembentukan Gas Metan: Pembentukan gas Metan dapat melalui 3 cara, yaitu: 1) melalui pengubahan atau perombakan asam-asam organik seperti Asam asetat oleh bakteri menjadi Metan. Pembentukan gas Metan yang terbanyak yakni sekitar 70\% adalah dari Asam asetat; 2) melalui oksida alkohol sederhana (Ethanol) oleh Karbon dioksida sehingga terbentuk Metan.

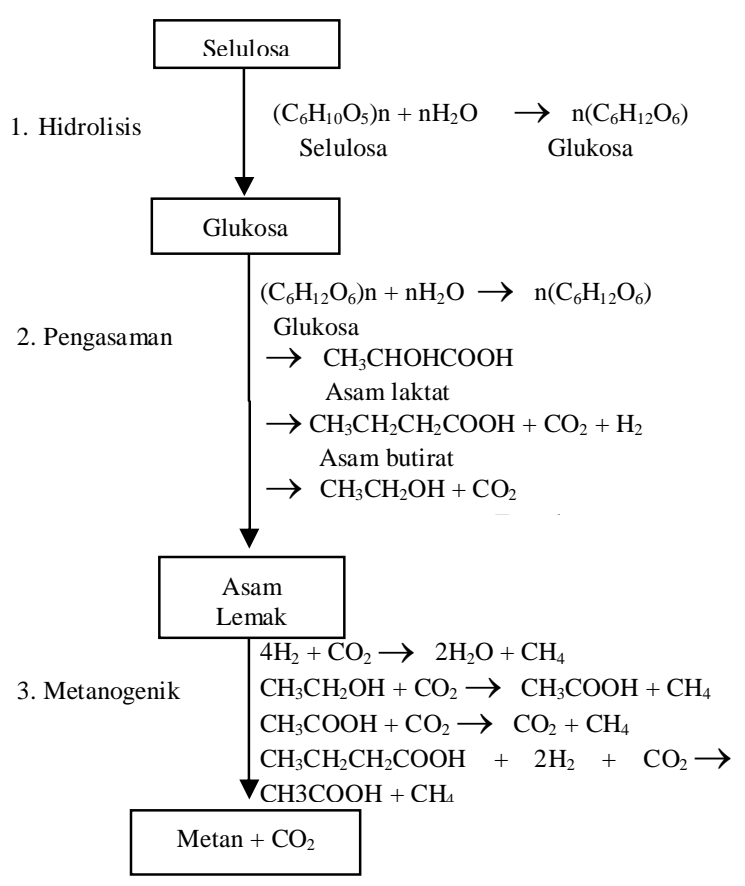

Gambar 1. Tahap Pembentukan Gas

\section{Gas Metan}

Gas Metan yang bergabung dengan $\mathrm{CO}_{2}$ atau gas Karbon dioksida yang kemudian disebut biogas dengan perbandingan 65 : 35 memerlukan persyaratan tertentu yang menyangkut:

1. Kandungan atau isi yang terkandung dalam bahan. Hal ini menyangkut nilai atau perbandingan antara unsur $\mathrm{C}$ (Karbon) dan unsur $\mathrm{N}$ (Nitrogen) yang secara umum dikenal dengan nama rasio $\mathrm{C} / \mathrm{N}$. Jika bahan yang digunakan berbentuk kotoran kandang, misalnya dari kotoran babi dengan rasio $\mathrm{C} / \mathrm{N}$ sekitar 18 , maka produksi biogas akan mempunyai bandingan antara $\mathrm{CH}_{4}$ dan $\mathrm{CO}_{2}$ seperti 90 : 10 atau nilai lainnya yang terlalu tinggi. Kadar air yang terkandung dalam bahan yang digunakan, juga seperti rasio $\mathrm{C} / \mathrm{N}$ harus tepat.

2. Temperatur yang diyakini sebagai temperatur optimum perkembangbiakan bakteri Metan adalah sekitar $35^{\circ} \mathrm{C}$. Dengan temperatur itu, proses pembuatan biogas akan berjalan sesuai dengan waktunya.

3. Kehadiran jasad pemroses atau jasad yang mempunyai kemampuan untuk menguraikan bahan-bahan yang akhirnya membentuk $\mathrm{CH}_{4}$ dan $\mathrm{CO}_{2}$.

4. Aerasi atau kehadiran udara (oksigen) selama proses dalam pembuatan biogas sama sekali tidak diperlukan.
Keberadaan udara menyebabkan gas $\mathrm{CH}_{4}$ tidak akan terbentuk. Untuk itu maka bejana pembuat biogas harus dalam keadaan tertutup rapat.

Masih ada beberapa persyaratan lain yang diperlukan agar menghasil biogas. Tetapi kelima syarat tersebut merupakan syarat dasar agar proses pembuatan biogas berjalan sebagaimana mestinya. ${ }^{[5]}$

\section{Jenis Reaktor Biogas}

Reaktor biogas dapat digolongkan dalam 2 jenis ${ }^{[10]}$ :

1. Berdasarkan konstruksinya, pada umumnya reaktor biogas dapat digolongkan dalam 2 jenis, yakni fixed dome dan floating drum.

a) Fixed dome mewakili konstruksi reaktor yang mewakili volume tetap sehingga produksi gas akan meningkatkan tekanan di dalam reaktor.

b) Floating drum berarti ada bagian pada konstruksi reaktor yang bisa bergerak untuk menyesuaikan dengan kenaikan tekanan reaktor.

2. Berdasarkan tipe alirannya, reaktor biogas dapat digolongkan dalam 2 jenis, yaitu:

a) Tipe batch (bak). Pada tipe bak, bahan baku reaktor ditempatkan di dalam wadah (ruang tertentu) dari awal hingga selesainya proses pencernaan.

b) Tipe mengalir (continuous). Pada jenis mengalir, ada aliran bahan baku dan residu keluar pada selang waktu tertentu.

Potensi produksi biogas dari beberapa jenis kotoran ternak yang merupakan dari hasil penelitian Pusat Penelitian Kopi dan Kakao Indonesia, ditampilkan pada tabel 2.

Table 2. Potensi Produksi Biogas dari Kotoran Ternak ${ }^{[7]}$

\begin{tabular}{|c|c|}
\hline Jenis Ternak & Produksi Gas $\left(\mathbf{m}^{\mathbf{3}} / \mathbf{k g}\right)$ \\
\hline Sapi dan Kerbau & $0,023-0,040$ \\
\hline Babi & $0,040-0,059$ \\
\hline Ayam & $0,065-0,116$ \\
\hline
\end{tabular}

\section{METODOLOGI PENELITIAN}

Metode penelitian yang digunakan pada penelitian tahun pertama ini adalah metode perancangan peralatan biogas, proses pengolahan kotoran ternak menjadi biogas.

Pada tahun pertama penelitian ini, hanya akan membuat instalasi biogas dan pengolahan kotoran ternak menjadi biogas. Penelitian ini diawali dengan pembuatan instalasi biogas kemudian proses produksi biogas dengan mencampurkan kotoran ternak dan air dengan perbandingan 1 : 1 yang dimasukkan ke dalam digester melalui lubang pengisian (inlet) hingga bahan yang dimasukkan ke digester ada sebagian yang keluar melalui lubang pengeluaran (outlet), selanjutnya akan berlangsung proses produksi biogas di dalam digester. Setelah 21-30 hari biogas yang terbentuk di dalam digester sudah cukup banyak.

Pengisian bahan biogas selanjutnya dilakukan setiap hari, yaitu sebanyak kira-kira $10 \%$ dari volume digester. Sisa pengolahan bahan biogas berupa sludge secara otomatis keluar dari lubang pengeluaran (outlet) setiap kali dilakukan pengisian bahan biogas. Sisa hasil pengolahan bahan biogas 
tersebut dapat digunakan sebagai pupuk kandang/pupuk organik, baik dalam keadaan basah maupun kering. Juga dapat digunakan sebagai media tanam jamur.

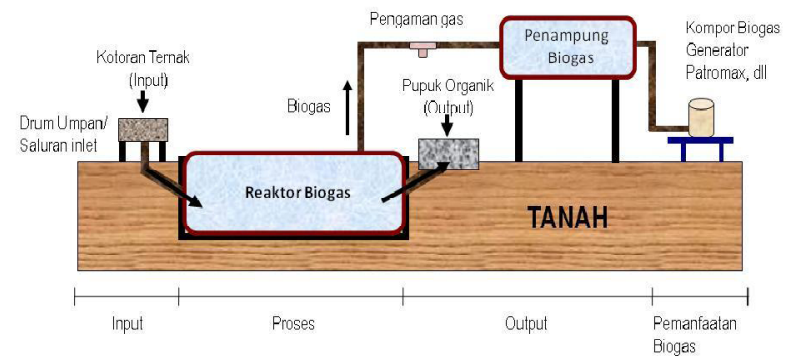

Gambar 2. Peralatan dan Proses Pengolahan Biogas ${ }^{[13]}$

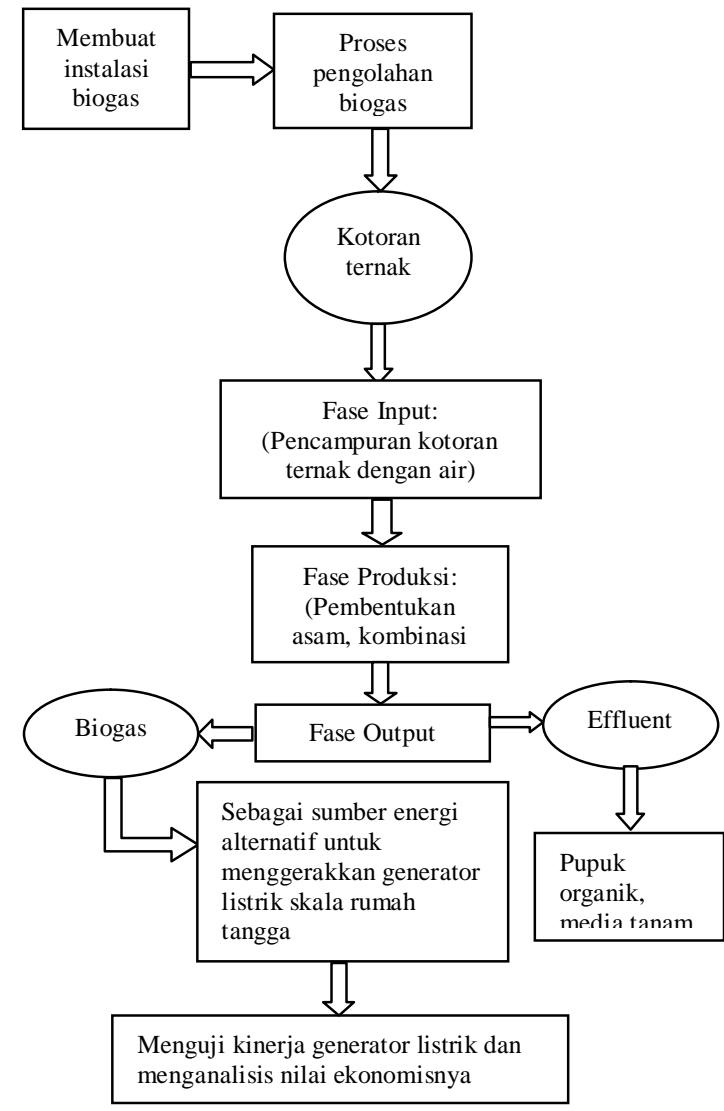

Gambar 3. Diagram Alir Proses Pengujian Biogas

\section{HASIL DAN PEMBAHASAN}

Kegiatan yang dilakukan di tahun pertama adalah membuat instalasi biogas dengan hasil yang telah dicapai seperti pada gambar 3.1. instalasi ini dibuat di lingkungan kampus UKI Toraja yang diharapkan bisa menjadi tempat penelitian bagi para dosen lain, mahasiswa dan masyarakat yang berminat untuk melakukan penelitian di bidang teknologi biogas ini.

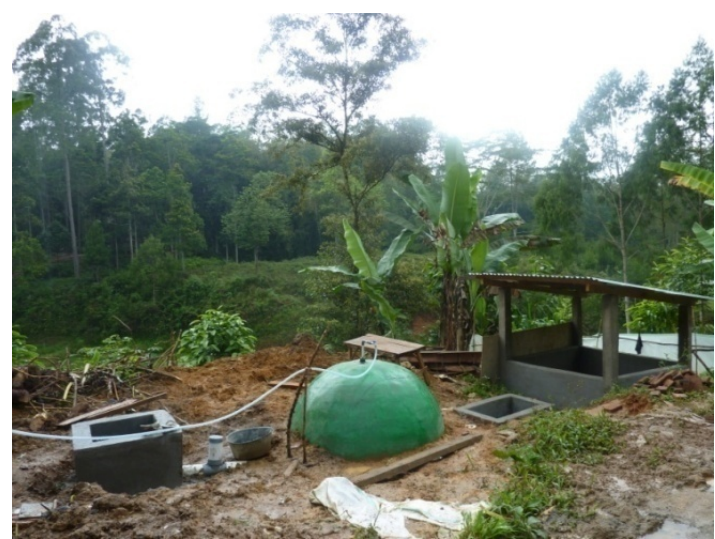

Gambar 4. Instalasi Biogas

Pada tahap selanjutnya dilakukan proses pengolahan kotoran ternak dengan membuat campuran kotoran ternak dan air dengan perbandingan 1 : 1 (bahan biogas). Kemudian mengalirkan bahan biogas (kotoran ternak dan air) ke dalam digester melalui lubang pengisian (inlet) hingga bahan yang dimasukkan ke digester ada sedikit yang keluar melalui lubang pengeluaran (outlet). Selanjutnya proses pembentukan gas terjadi pada hari ke-29 hingga terlihat adanya gas menempati plastik penampungan biogas kemudian dilakukan uji nyala untuk memastikan bahwa gas Metan telah terbentuk.

Adapun penentuan volume gas dapat dihitung sebagai berikut:

Diketahui kapasitas tangki yang digunakan adalah 2000 liter dan kapasitas kubah gas 1000 liter.

Pada percobaan pertama dilakukan pencampuran kotoran dan air yang dihasilkan dari 8 ekor kerbau dengan total jumlah kotoran basah rata-rata $61,4 \mathrm{~kg} / \mathrm{hari}$ (masa pengukuran 30 hari).

Dari data Potensi produksi biogas dari kotoran kerbau berdasarkan hasil penelitian dari Pusat Penelitian Kopi dan Kakao Indonesia diketahui berkisar $0,023 \mathrm{~m}^{3} / \mathrm{kg}$ hingga $0,040 \mathrm{~m}^{3} / \mathrm{kg}$.

Diasumsi gas yang dihasilkan dari hasil penelitian ini adalah $0,030 \mathrm{~m}^{3} / \mathrm{kg}$.

Jadi volume biogas per $\mathrm{kg}$ kotoran kerbau perhari $=61,4 \mathrm{~kg}$ $\mathrm{x} 0,030 \mathrm{~m}^{3} / \mathrm{kg}=1,84 \mathrm{~m}^{3} /$ hari.

Pada percobaan kedua dilakukan pencampuran kotoran dan air yang dihasilkan dari 21 ekor babi dengan total jumlah kotoran basah rata-rata $25,10 \mathrm{~kg} /$ hari (masa pengukuran 28 hari).

Dari data Potensi produksi biogas dari kotoran babi berdasarkan hasil penelitian dari Pusat Penelitian Kopi dan Kakao Indonesia diketahui berkisar $0,040 \mathrm{~m}^{3} / \mathrm{kg}$ hingga $0,059 \mathrm{~m}^{3} / \mathrm{kg}$.

Diasumsi gas yang dihasilkan dari kotoran babi pada penelitian ini adalah $0,040 \mathrm{~m}^{3} / \mathrm{kg}$.

Jadi volume biogas per $\mathrm{kg}$ kotoran babi perhari $=25,10 \mathrm{~kg}$ x $0,040 \mathrm{~m}^{3} / \mathrm{kg}=1,004 \mathrm{~m}^{3} /$ hari.

Diketahui: $1 \mathrm{~m}^{3}$ biogas setara dengan Elpiji [0,46 kg], Minyak Tanah [0,62 Liter], Minyak solar [0,52 liter], Bensin [0,80 liter] dan kayu bakar [3,50 kg].

Hasil yang kami peroleh saat ini masih dalam batas perkiraan oleh karena itu untuk penelitian selanjutnya yaitu variable campuran kotoran babi dan kerbau sangat 
dibutuhkan alat Biogas flow-meter sehingga dapat diperoleh hasil yang lebih akurat.

\section{KESIMPULAN}

1. Instalasi biogas yang terdiri dari bak inlet, digester 3 $\mathrm{m}^{3}$, bak outlet dan rumah kompos dibangun dalam waktu kurang lebih 1 bulan.

2. Perkiraan volume biogas yang diperoleh dari 8 ekor kotoran kerbau per hari adalah sekitar $1,84 \mathrm{~m}^{3} /$ hari sedangkan untuk kotoran yang dihasilkan dari 21 ekor babi diperoleh volume biogas sekitar 1,004 $\mathrm{m}^{3} /$ hari.

\section{DAFTAR PUSTAKA}

[1] Antara News. 21 Juli 2009.Toraja Utara Waspadari Babi dari Luar.Diakses 30 Juli

2013.http://makassar.antaranews.com/berita/5901/tor aja-utara-waspadai-babi-dari-luar

[2] Biro Pusat Statistik Kabupaten Tana Toraja. 2006. Populasi Ternak Babi di Sulawesi Selatan

[3] Gerardy, M. 2003, The Microbiology of Anaerobic Digestion, John Wiley and Sons, Inc., New Jersey, ISBN: 0-471-20693-8

[4] Ginting, Nurzainah, Ir., M.Sc. 2007. Penuntun Praktikum Teknologi Pengolahan Limbah Peternakan, Departemen Peternakan Fakultas Pertanian Universitas Sumatera Utara

[5] Hermawan, Beni, dkk. 2008. Sampah Organik sebagai Bahan Baku Biogas. Available from: http://www.chem-is-try.org/?sect=fokus\&ext=31. Diakses 2 Maret 2012.

[6] Indarto, S, Yuli. 2005. Reaktor Biogas Skala Kecil/Menengah. Available from: http://www.beritaiptek.com/zberita-beritaiptek-200511-30-Reaktor-Biogas-Skala-

Kecil\%20or\%20Menengah-(Bagian-Pertama).shtml. Diakses 1 Maret 2012

[7] Informasi Paket Teknologi, Produksi Biogas dari Limbah Ternak.

http://pustaka.litbang.deptan.go.id/agritek/kopi08.pdf, diakses 29 November 2013

[8] Musanif, Jamil, dkk. 2006. Biogas Skala Rumah Tangga, Program Bio Energi Pedesaan, Direktorat
Pengolahan Hasil Pertanian, Ditjen Pengolahan dan Pemasaran Hasil Pertanian, Departemen Pertanian

[9] Nawan \& Lusyawati. 2012. Kompor Biogas. Available from: http://komporbiogasnawan38.blogspot.com/2012/07/merancang-instalasibiogas.html. Diakses 28 Mei 2013

[10] Ni Nyoman Santi.2008. Pemanfaatan Kotoran Ternak Skala Rumah Tangga sebagai Sumber Energi Alternatif Biogas. Artikel

[11] Nursanty, Lina. 2010. Menghamburkan Listrik Murah. Available from: $\underline{\text { http://bataviase.co.id/node/149223. Diakses } 2 \text { Maret }}$ 2012

[12] Pambudi, N. Agung. 2008. Pemanfaatan Biogas sebagai Energi Alternatif. Available from:http://www.dikti.org/?q=node/99. Diakses 23 Februari 2012

[13] Subdit Pengelolaan Lingkungan, Direktorat Pengolahan Hasil Pertanian Direktorat Jenderal Pengolahan dan Pemasaran Hasil Pertanian Departemen Pertanian. 2009

[14] Wahyuni, Sri. 2009. "Biogas" Sumber Biogas, Penebar Swadaya 